\title{
A EDUCAÇÃO INTERDIMENSIONAL NA ORGANIZAÇÃO PEDAGÓGICA DE UMA ESCOLA DE ENSINO INTEGRAL: 0 aprender a conviver no Projeto Político-Pedagógico
}

\author{
ALBERTO GUERRA DE LIMA \\ Universidade de Pernambuco (UPE). Mestre em Educação pela Universidade de \\ Pernambuco. Professor da Secretaria de Educação e Esportes de Pernambuco. \\ ORCID: 0000-0001-6370-9277. E-mail: guerra_lima_pe@hotmail.com
}

\section{LUIZ ALBERTO RIBEIRO RODRIGUES}

Universidade de Pernambuco (UPE). Doutor em Educação pela Universidade Federal de Pernambuco. Professor Adjunto da Universidade de Pernambuco. ORCID: 0000-0002-3151-1685. E-mail: luiz.rodrigues@upe.br 


\section{A EDUCAÇÃO INTERDIMENSIONAL NA ORGANIZAÇÃO PEDAGÓGICA DE UMA ESCOLA DE ENSINO INTEGRAL: o aprender a conviver no Projeto Político-Pedagógico}

O objetivo deste artigo é apontar propostas de melhoria na organização da prática pedagógica de uma escola de referência em ensino médio, a qual faz parte do Programa de Educação Integral, no estado de Pernambuco, através da estratégia do aprender a conviver, da Educação Interdimensional. Portanto, procedeu-se a um levantamento bibliográfico, baseado em estudos, como os de Costa (2001), Gadotti (2009) e Veiga (2003), partindo posteriormente a uma revisão de seu Projeto Político-Pedagógico, ao inserir nele, os princípios do modelo pedagógico interdimensional. A decisão de revisar o projeto originou-se das descobertas obtidas em uma recente pesquisa de natureza qualitativa, realizada na referida escola, baseada na metodologia da pesquisa ação. A pesquisa contou com a colaboração de um grupo focal na coleta e análise dos dados obtidos. Percebeu-se que a reorganização do Projeto Político-Pedagógico pode contribuir com a prática pedagógica da escola, além de incentivar o protagonismo juvenil do estudante, assim como servir para nortear as ações da gestão escolar.

Palavras-chave: Educação Interdimensional. Aprender a Conviver. Projeto Político-Pedagógico.

\section{INTERDIMENSIONAL EDUCATION IN THE PEDAGOGICAL ORGANIZATION OF A SCHOOL OF INTEGRAL EDUCATION:learning to live together in the Political-Pedagogical Project}

The objective of this article is to present proposals for improvement in the organization of the pedagogical practice of a reference high school, which is part of the Integral Education Program, in the state of Pernambuco, through the strategy of learning to live together, of the Interdimensional Education. Therefore, a bibliographic survey was carried out, based on studies, such as those of Costa (2001), Gadotti (2009) and Veiga (2003), with a subsequent review of the Political-Pedagogical Project, by inserting the principles of the interdimensional pedagogical model into it. The decision to review the project came from the findings collected in a qualitative research, conducted at the school, based on the methodology of action research. The research had the collaboration of a focus group in the gathering and analysis of the collected data. It was noticed that the reorganization of the Political-Pedagogical Project can contribute to the pedagogical practice of the school, in addition to fostering the youth protagonism of the student, as well as to serve to guide the actions of school management.

Keywords: Interdimensional Education. Learning to Live Together. Political-Pedagogical Project. 


\section{LA EDUCACIÓN INTERDIMENSIONAL EN LA ORGANIZACIÓN PEDAGÓGICA DE UNA ESCUELA INTEGRAL: aprender a convivir en el Proyecto Político-Pedagógico}

El objetivo de este artículo es señalar propuestas de mejora en la organización de la práctica pedagógica de una escuela de referencia en la enseñanza secundaria, que forma parte del Programa de Educación Integral, en el estado de Pernambuco, a través de la estrategia de aprender a convivir, de la Educación Interdimensional. Por lo tanto, se realizó una investigación bibliográfica basada en estudios como los de Costa (2001), Gadotti (2009) y Veiga (2003), iniciando más tarde una revisión de su Proyecto PolíticoPedagógico, insertando en él los principios del modelo pedagógico interdimensional. La decisión de revisar el proyecto se originó en los descubrimientos obtenidos en una reciente investigación cualitativa, llevada a cabo en esa escuela, basada en la metodología de la investigación-acción. La pesquisa contó con la colaboración de un grupo focal en la colecta y análisis de los datos obtenidos. Se constató que la reorganización del Proyecto Político-Pedagógico puede contribuir a la práctica pedagógica de la escuela, además de fomentar el protagonismo juvenil del alumno, así como servir para orientar las acciones de la dirección de la escuela.

Palabras clave: Educación interdimensional. Aprender a Convivir. Proyecto Político-Pedagógico.

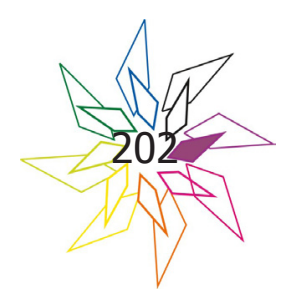




\section{A EDUCAÇÃO INTERDIMENSIONAL NA ORGANIZAÇÃO PEDAGÓGICA DE UMA ESCOLA DE ENSINO INTEGRAL: o aprender a conviver no Projeto Político-Pedagógico}

\section{Introdução}

As recentes políticas nacionais na educação básica têm apontado na direção de uma crescente oferta de escolas de ensino integral. A meta número 6 do Plano Nacional de Educação 2014, prevê que sejam criadas até 50\% das escolas públicas, nesta modalidade de ensino (BRASIL, 2014). Para que essa educação seja vivenciada de maneira integral, em seu sentido pleno, faz-se necessário pensar de que forma a organização pedagógica da escola seja posta em prática, de modo que se constitua em uma proposta consolidada e eficiente.

O presente estudo se originou de uma recente pesquisa de mestrado profissional, na qual se observou a contribuição da proposta pedagógica da Educação Interdimensional, a partir de agora EI, na mediação de conflitos em uma escola integral, situada na zona da mata norte de Pernambuco. As descobertas evidenciaram que as relações interpessoais nesta escola foram bastante influenciadas por essa educação humanista, embora tenha sido notado que seu Projeto Político-Pedagógico não preconizasse a necessidade de que tal pedagogia estivesse de forma perene, no dia-a-dia da instituição de ensino.

O objetivo deste artigo é apontar propostas de melhoria na organização da prática pedagógica de uma escola de referência em ensino médio, a qual faz parte do Programa de Educação Integral, no estado de Pernambuco, através da estratégia do aprender a conviver, da Educação Interdimensional, enquanto estratégia para a mediação de conflitos na rotina escolar.

Da mesma forma, procura-se observar os desafios da gestão escolar na condução desse modelo de escola, em uma perspectiva democrática, assim como a forma pela qual a EI tem sido vivenciada, a fim de se estabelecer uma educação de qualidade social, centrada em valores e de cultura de paz, para a mediação de conflitos na escola.

Ainda na direção da gestão democrática, é feita uma reflexão em torno da importância da participação da comunidade escolar nas decisões relativas à organização pedagógica da escola,

\section{plupais}


assegurando o protagonismo de seus atores. Estas questões demonstraram ter sido contempladas ao longo da condução das etapas da pesquisa.

Por fim, proceder-se-á a uma conceptualização atualizada a respeito do PPP e da organização pedagógica da escola. Tal processo será evidenciado por meio dos passos para a reelaboração do PPP, a partir dos princípios da EI, do destaque a seus valores norteadores, da orientação para o projeto de vida do estudante, e particularmente da vivência do aprender a conviver.

\section{Os desafios da gestão democrática na elaboração do PPP, em um contexto gerencialista}

A maneira como a educação vem sendo influenciada ultimamente pelas políticas de resultados, tem provocado questionamentos sobre o perfil de escola que se deseja nestes novos tempos: que objetivos ela busca; de que maneira ela pode atender a seu público; como oferecer a seus estudantes uma educação emancipadora e significativa; visto que se almeja neste modelo de escola, a formação de jovens autônomos, enquanto pessoa, solidários, enquanto cidadãos e competentes, quando oportunamente desempenharem suas atividades acadêmicas ou profissionais. Esta escola deve ser aquela que "continuadamente se pensa a si própria, na sua missão social e na sua organização" (ALARCÃO, 2001).

No entanto, os rumos da educação nem sempre seguem a direção das afirmações anteriores, pois a escola tem tido dificuldade para seguir as mudanças ocorridas na sociedade. Mesmo com as eventuais transformações pelas quais tem passado, ela ainda não é atrativa. É 'coisa do passado', que não prepara o aluno para o atual mundo de complicações, que o predispõe a um pensamento lógico e racional. (IDEM)

É necessária, então, uma mudança significativa na escola. Segundo Alarcão (2001), tal modificação não deve ser somente curricular, mas em sua organização pedagógica, disciplinar e organizacional. Repensando a forma como ela é contextualizada, no entanto com ações práticas.

Ao mesmo tempo em que são apresentados desafios institucionais e pedagógicos à escola, as políticas da atualidade, apresentam um novo modelo de gestão gerencial, o qual defende a qualidade do ensino, a partir da eficiência e atingimento de metas. Surge, então, a exigência de que a

\section{plurais}

Salvador, v. 5, n.3, p. 200-222, set./dez. 2020

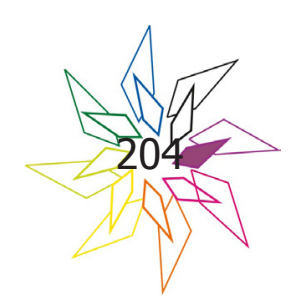


gestão seja também eficiente, com uma visão baseada na liderança, autonomia e descentralização. (FONSECA, 2004)

A busca pela eficiência, faz com que o gestor se envolva em valores alheios à perspectiva democrática. Nesse sentido, este modo gerencial acaba por modificar o caráter da linguagem utilizada pelos profissionais ao tratar da mudança. Para Shiroma e Campos (2006) tal discurso vai exercer influência tanto na linguagem, quanto na prática escolar. Uma mudança no perfil de professor e diretor de escola.

Na direção de uma gestão escolar democrática, em que o diretor escolar exerce a atividade fim, que é a pedagógica, podemos vislumbrar tal gestão como um espaço repleto de aprendizagens e formação cidadã dos estudantes, em que se exerce a corresponsabilidade por dirigir a escola. Assim, na organização da prática pedagógica da escola, o gestor é o mediador entre a coletividade da escola e seus sujeitos sociais, ou seja, aqueles a quem se destina a educação.

De acordo com Sposito (2005, p. 55) " a gestão democrática deve ser um instrumento de transformação das práticas escolares, não a sua reiteração. Este é o seu maior desafio, pois envolverá, necessariamente, a formulação de um novo projeto pedagógico."

O gestor escolar, na perspectiva democrática é, portanto, aquele que propicia as condições para que a comunidade escolar participe do processo de organização pedagógica. Ao trabalhar no coletivo, ele descentraliza decisões, torna-se o articulador democrático da instituição, pois uma gestão que se considere democrática, compromete-se com toda a comunidade escolar.

Para Paiva (2018), é preciso considerar que a gestão escolar no paradigma democrático se realiza em projetos, e que estes colaboram com a organização em que o administrador se atenta para o trabalho feito na coletividade. Constitui-se então, como papel do gestor, promover a participação da comunidade nas decisões, ao mesmo tempo em que é legalmente autônomo para organizar os trabalhos da comunidade escolar, assim como outras atribuições pedagógicas (RODRIGUES, 2016).

Nessa perspectiva, o PPP é um instrumento importante na organização do trabalho pedagógico e da construção do conhecimento dos estudantes, e que exige a participação de toda a comunidade escolar. O gestor escolar adquire nesta conjuntura a responsabilidade de mobilizar todos para elaborar, desenvolver e avaliar o projeto (ALARCÃO, 2001).

\section{plurais}


Portanto, para esta autora, o PPP tem sua dimensão pedagógica "na intencionalidade da escola para desenvolver ações a fim de cumprir sua finalidade de formar cidadãos nas dimensões sociocultural, política, profissional e humana” (IDEM, p. 78).

A construção deste projeto representa a grande realização da comunidade escolar no chão da escola, reflexiva e emancipadora. É a expressão da constituição do currículo que resume a organização do conhecimento escolar à procura de um ensino de qualidade social. (ALARCÃO, 2001). Importa, então, refletir acerca das bases do PPP e sua contribuição nesta organização da prática pedagógica em uma escola de educação integral.

\section{Participação e protagonismo no Projeto Político-Pedagógico}

Muitos autores têm se dedicado a pesquisar e produzir, sobre formas de fazer com que o PPP das escolas seja cada vez mais eficaz, eficiente e contextualizado, não apenas o documento que cumpre exigências legais. A organização pedagógica de uma escola de referência possui peculiaridades que emanam da filosofia interdimensional. Isto provoca a necessidade do PPP destas escolas estar alinhado com os princípios da EI, particularmente o pilar do Aprender a Conviver, o qual é balizador das relações interpessoais, vivenciadas neste modelo de escola.

A Lei de Diretrizes e Bases da Educação Nacional (LDBEN 9.394/96), prevê e fixa, no inciso I do Artigo 12, as responsabilidades e incumbências das escolas na elaboração e execução do seu PPP. No inciso III, do Art. 32, esta lei estabelece como princípio de toda educação nacional, a exigência de "pluralismo de ideias e de concepções pedagógicas". Portanto, legalmente, a orientação do PPP é muito bem embasada, ainda que necessite do compromisso daqueles que participam de sua elaboração, para que ele seja um documento vivo no cotidiano escolar.

A origem etimológica de projeto vem do latim: projectu, ou seja, lançar à frente. É sinônimo de esquema, traçado, plano ou programação (PAIVA, 2018). Para Gadotti (1998), é o"lançar-se para a frente", procurando vislumbrar um futuro distinto do que se tem na atualidade, além de ser pressuposto de uma ação intencionada com vistas a uma inovação.

O termo político tem sua origem no grego politikos, que significa cívico, originário de polites, cidadão, que por sua vez surgiu do termo polis, que é cidade. Para Veiga (2013) a palavra, político, indica o senso de comprometimento com a formação cidadã, voltada para um certo tipo de

\section{plurais}

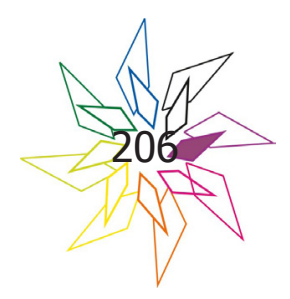


sociedade. Paiva (2018) fecha este esmiuçamento etimológico do PPP, com a definição do que vem a ser pedagógico, ou seja, a composição das palavras gregas paidos, que quer dizer criança, e gogía que se refere à condução ou acompanhamento, que à época da Grécia antiga, era feita por escravos.

Após se compreender a concepção do que vem a ser o pedagógico no PPP, deduz-se que a real intencionalidade da escola deve situar-se no pedagógico. Nesta dimensão percebe-se a formação do cidadão, que se mostra participativo, crítico e, como explicita Veiga (2013), é protagonista de sua própria história, característica almejada na Educação Interdimensional. Estes valores de participação, autonomia e protagonismo juvenil podem atribuir ao PPP de uma escola integral, um diferencial no que é preconizado para uma instituição deste perfil.

Para Libâneo (2001), o PPP, além de expressar sinteticamente as exigências sociais e legais do sistema de ensino, também expressa os propósitos e expectativas da comunidade escolar. O PPP tem sua elaboração em meio a negociações entre os indivíduos participantes do ambiente escolar. A finalidade deste processo é a organização e planejamento do trabalho pedagógico e também administrativo da escola, em busca de soluções para as necessidades desta instituição de ensino (TINEU et al., 2013).

Importa destacar que o processo de mobilização da comunidade escolar, demanda do gestor uma atitude proativa, que motive a equipe para participar ativamente, de maneira espontânea. A respeito da participação no contexto escolar, é notável a tarefa da gestão democrática e participativa em se abrir ao debate e propor soluções para as necessidades da escola. Valorizando sua participação, para que ele se sinta disposto a conduzir a escola em direção à educação de qualidade social (SILVA, 2018).

Ao se projetar algo, a tendência é que se saia de uma zona de conforto, tarefa nada fácil no mundo pragmático atual, em que os educadores se veem às voltas com tantas demandas no trabalho. No entanto, a pessoa do gestor, enquanto mobilizador, deve trazer sua equipe à consciência de "quebrar um estado confortável para arriscar-se em algo novo, ainda não estável, mas buscando um futuro melhor do que o presente" (TINEU et al., 2013, p. 2).

\section{Os procedimentos para a revisão do Projeto Político-Pedagógico}

O PPP é um documento que lida com o ordenamento das ações que ocorrem no cotidiano escolar. Ele é a referência para as decisões que serão tomadas durante seu período de vigência. Para Paiva (2018), é um documento central, que apoia a gestão escolar, legitima as gestões democráticas 
na escola, além de organizar o trabalho pedagógico, auxiliando na conquista de objetivos educacionais e participação da comunidade.

É necessário, então, um planejamento feito por etapas e, principalmente, da participação da comunidade escolar, para que adquira um perfil emancipatório e democrático. É preciso ter vontade política para realizar esta tarefa, que não é nada fácil, no entanto, como explicita Paiva (2018), com ação e reflexão ativos, partilhando as ideias, ele não será mais um documento guardado no arquivo escolar.

O PPP da escola analisada havia sido feito, de forma generalista e descontextualizada, possivelmente, a partir de modelos emprestados de outras instituições, a fim de cumprir a formalidade para a criação da EREM, em 2007. Em 2015, a partir da iniciativa do novo gestor escolar, foi iniciado um processo de planejamento para a revisão do mesmo. Foram então criados grupos de trabalho, compostos por membros da comunidade escolar, que ficaram incumbidos de propor alterações e atualizações legais, coordenados pela educadora de apoio.

Em seguida, os grupos se reuniram em plenária para formatar o projeto. A intenção da equipe foi que o PPP tivesse uma redação clara, simples, e acessível a qualquer pessoa que o consultasse, e que refletisse de fato o contexto da escola, além do alinhamento com a proposta pedagógica de uma escola de referência.

No entanto, apesar de se ter alcançado os objetivos propostos pela gestão e coordenação pedagógica, faltou ao PPP a explicitação de seu referencial teórico. O que veio a ser observado apenas após o desenrolar desta pesquisa. Este referencial seria um alicerce para o que fora construído na coletividade, que fundamentasse a elaboração do PPP da escola (PAIVA, 2018). Considerando-se a filosofia pedagógica de uma EREM, era de se esperar que ela estivesse presente ao longo de todo o documento.

Decerto que os professores e outros participantes da redação do documento tinham em mente os princípios da EI, porém não foi o suficiente para que a orientação interdimensional fosse amplamente prevista no PPP. A partir daí, surgiu a iniciativa de, a partir das descobertas feitas pelo pesquisador, elaborar uma proposta de revisão do PPP com um referencial teórico feito a partir dos princípios da EI, particularmente o Aprender a Conviver, aliados à educação para a paz e mediação de conflitos escolares.

\section{plurais}

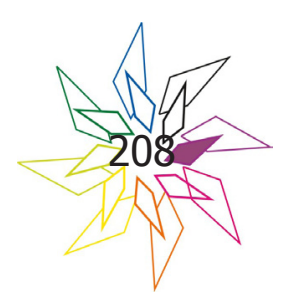


Faltava então, à atual versão, desde sua parte introdutória, que a escola assumisse ser espaço de formação plena do estudante. Que se esperasse dele um desenvolvimento na integralidade de suas dimensões pessoais e que o conflito fosse uma variável presente e aceita no seu dia-a-dia, porém que a boa convivência entre seus membros pudesse mitigar tais conflitos e fortalecer as relações interpessoais.

Esperava-se também que o aprender a conviver estivesse nos seus princípios educacionais, representando a cultura de paz na escola. Nos princípios pedagógicos, a presença do Projeto de Vida do educando, o preparando para estar apto às exigências do mundo do trabalho e da sociedade da informação do século XXI.

Dessa forma, foi necessário estabelecer duas premissas para o processo educacional dos estudantes. As estratégias pedagógicas da Pedagogia da Presença e do Protagonismo Juvenil, consolidam o aprender a conviver, a cultura de paz e desenvolvimento da autonomia do educando. Mesmo que já estivesse na cultura escolar, a presença educativa e o incentivo à promoção de práticas protagonistas, por parte dos educadores, com a formalização e intencionalidade destas estratégias, o PPP estaria mais enriquecido e vivo na escola.

O impacto esperado após estas mudanças seria o fortalecimento do PPP da escola, a legitimação das decisões e atitudes tomadas pela gestão, junto aos pais e professores, a promoção da cultura de paz, inserido em uma educação voltada a práticas pacíficas de boa convivência em meio aos conflitos, violências e outros desafios que surgissem.

Outro benefício deste novo perfil de PPP, é que, consequentemente, esta série de mudanças que ocorreriam no chão da escola e na formação moral dos estudantes, se refletiriam além dos muros da escola. Este é um dos papéis principais de uma instituição de ensino que produz uma educação de qualidade: entregar à sociedade civil, jovens aptos a enfrentar os desafios da vida adulta, com valores sólidos de respeito, solidariedade, tolerância, fibra e autonomia.

\section{O Projeto de Vida na organização pedagógica da escola}

Considerando-se que as condições para se estabelecer as mudanças pretendidas para o ambiente escolar, foram previstas, chega o momento de se pensar em que estratégias serão úteis à consecução da proposta pedagógica. O conjunto de atividades pedagógicas que serão indicadas, poderão enriquecer a práxis da escola e dar um novo significado ao PPP da escola.

\section{plurais}


No início da experiência pernambucana em educação integral, com os Centros de Ensino Experimental em 2004, a Secretaria de Estadual de Educação teve a importante parceria do Instituto de Corresponsabilidade pela Educação (ICE). Esta organização prestou assistência técnica e pedagógica ao projeto. No entanto, a partir de 2007, com a criação do Programa de Educação Integral, a consultoria do ICE foi interrompida, ficando a cargo do próprio programa a condução pedagógica das escolas em tempo integral.

A menção ao ICE neste estudo se justifica pelo fato de que, desde que o Progama de Educação Integral tomou a frente do planejamento pedagógico das EREMs, acabou descontinuando algumas das práticas que o ICE havia implementado nos Centros Experimentais. A orientação pedagógica das EREMs ficou restrita às formações continuadas em Educação Interdimensional. No entanto, O ICE permanece prestando assessoria a outros estados da federação, que iniciaram seus programas em educação integral, a exemplo de São Paulo, Sergipe e Acre, entre outros 14 estados (ICE, 2019).

A forma de organização pedagógica vivenciada nestas escolas integrais está em sintonia com o que preconiza a lei do Novo Ensino Médio (Lei 13.415/2017), em seu artigo sétimo, o qual prevê que: "Os currículos do ensino médio deverão considerar a formação integral do aluno, de maneira a adotar um trabalho voltado para a construção de seu Projeto de Vida e para sua formação nos aspectos físicos, cognitivos e socioemocionais" (BRASIL, 2017, p. 2).

Assim, o ICE, baseando-se em seu pressuposto de inovação em conteúdo, método e gestão, apresenta como ações do modelo pedagógico integral, o acolhimento dos estudantes no primeiro dia de aula, assim como aos pais e professores, tutoria, práticas e vivências em protagonismo, estudo orientado, disciplinas eletivas, práticas experimentais, aulas de Projeto de Vida, além de outras práticas voltadas à gestão (ICE, 2015).

O Projeto de Vida consiste de uma série de atividades desenvolvidas com os estudantes, nas quais se trabalha a conscientização sobre como planejar sua vida acadêmica e profissional, após o ensino médio.

A inclusão do Projeto de Vida na organização pedagógica é uma importante estratégia, visto que já integra a parte diversificada do currículo das EREMs, junto com Empreendedorismo

\section{plurais}

Salvador, v. 5, n.3, p. 200-222, set./dez. 2020

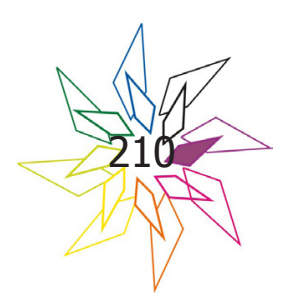


(DUTRA, 2019. Pg.18). O momento ideal para se trabalhar o Projeto de Vida é no $2^{\circ}$ ano do ensino médio, quando o educando já se encontra adaptado à nova escola.

Figura 1 - Elementos que constituem o Projeto de Vida do educando

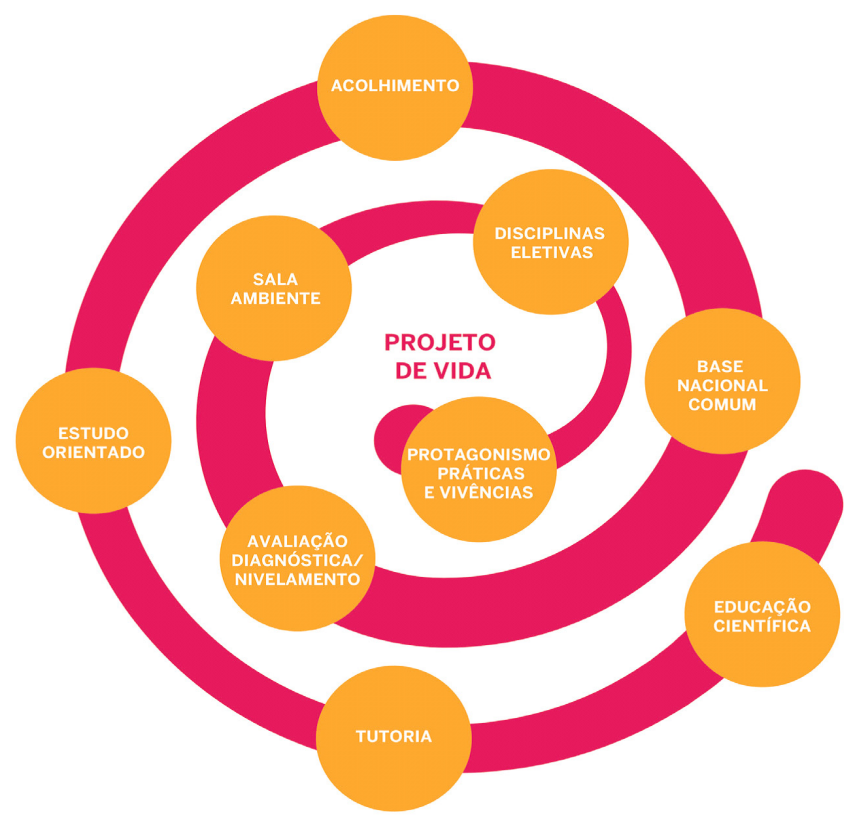

Fonte: ICE (2015)

O projeto das escolas integrais de Pernambuco também oportuniza estas atividades aos estudantes, porém com terminologias diferentes. No entanto, as práticas e vivências protagonistas, o estudo orientado e as aulas de Projeto de Vida, não vinham ocorrendo do modo esperado, particularmente na escola pesquisada. As disciplinas eletivas foram introduzidas recentemente, com vistas a contemplar o novo desenho curricular do ensino médio nacional.

Pretende-se, então, que as práticas até então deficientemente aplicadas, possam ser revistas e façam parte do desenvolvimento integral dos educandos. Pois, como afirma Gadotti (2009), a 
educação integral não se resume a estar em horário integral, mas ter a possibilidade de desenvolvimento de todas as potencialidades humanas.

O modelo proposto pelo ICE define três eixos para a realização da prática pedagógica, que coexistem, sem se sobrepor ao outro. São eles: a formação acadêmica de excelência, a qual se dá a partir de práticas eficazes de ensino e verificação de processos de aprendizagem, que asseveram o pleno domínio do conhecimento desenvolvido na Educação Básica, pelo estudante; a formação de competências para o século XXI, que destaca que a formação integral ocorre tanto por meio de um currículo pleno de competências cognitivas, quanto por possuir um conjunto de outras competências essenciais nos domínios da emoção e da natureza social (ICE, 2015).

A formação para a vida é o terceiro eixo. Ela resgata e amplia as referências do jovem no que se refere aos valores e princípios que contribuirão para a constituição de uma base sólida em sua formação (IDEM). Muitas vezes professores e pais acabam por supervalorizar a opção da vida acadêmica aos estudantes que concluem o ensino médio, como se este fosse o melhor caminho a seguir na vida. No entanto, há que se considerar que a educação integral visa ao desenvolvimento do jovem para que ele seja autônomo o suficiente para fazer suas próprias escolhas, muitas vezes este jovem quer optar por seguir diretamente para o mercado de trabalho, e lá exercer sua cidadania e valores aprendidos na escola.

Segundo Costa (2006), na preparação do seu Projeto de Vida, o educando precisa ser fonte de iniciativa, considerando-se que ele não seja apenas expectador dos seus processos de aprendizagem e vivências de experiências, pelo contrário, deve participar de sua produção. Além disso, ele deve ser fonte de liberdade, ao reconhecer oportunidades oferecidas a ele, para avaliar e fazer suas escolhas, a fim de promover seu crescimento como pessoa e cidadão. Finalmente, espera-se que ele seja tratado como fonte de compromisso, pois ele deve reconhecer em si mesmo, a responsabilidade por suas decisões e ações, sendo consequente, respondendo pelo que faz ou deixa de fazer.

O Projeto de Vida constitui-se, portanto, em uma forma eficiente e significativa de promover a organização pedagógica, refletido no PPP da escola. Isto pode assegurar a formação do jovem:

- autônomo, porque deverá ser capaz de avaliar e decidir baseado nas suas crenças, conhecimentos, valores e interesses;

\section{plurais}

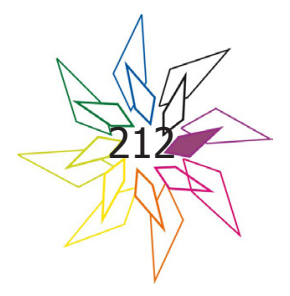


- solidário, porque deverá ser fonte de solução, de iniciativa, de ação e de compromisso associado a responsabilidades;

- competente, porque deverá ser capaz de projetar uma visão de si próprio no futuro, amadurecendo gradativamente um processo decisório sobre aquilo que deseja para a sua vida. (ICE, 2015. p. 13).

\section{A reorganização do PPP na perspectiva Interdimensional}

Conforme o que foi explicitado anteriormente, a escola pesquisada carecia de que as bases interdimensionais estivessem de forma intencional no seu PPP. A organização estrutural do PPP analisado era então composta pelas características da escola, seus níveis e modalidades de ensino, horário de funcionamento, seus princípios educativos (filosóficos e pedagógicos), a missão, organização do ensino, administração e princípios de convivência social.

Segundo Paiva (2018), a elaboração do PPP necessita de um referencial teórico por alicerce, a fim de permitir que se construam soluções para os problemas da comunidade escolar, pela coletividade. Da mesma forma, é preciso que se estabeleça objetivos, que possam enfrentar obstáculos. Em relação a isso, Gadotti (2000) faz referência à necessidade de tempo: político, institucional, escolar, até mesmo o tempo de amadurecimento das ideias. O referencial teórico e o tempo são importantes, mas além deles, deve-se levar em conta fatores que consistem, tanto de uma comunicação eficiente, adesão voluntária, suporte institucional e financeiro, quanto de controle, acompanhamento e avaliação do projeto e atmosfera, além da credibilidade do projeto (GADOTTI, 2000).

De acordo com Veiga (2013), há sete elementos importantes para fazer parte do PPP. São eles: finalidades, estrutura organizacional, currículo, tempo escolar, processo de decisão, relação de trabalho e avaliação. A partir deles proceder-se-á a uma análise das propostas de Paiva (2018), em contraponto ao modelo adotado pela escola pesquisada, indicado pela SEEP.

As finalidades são estabelecidas pela escola para formar o cidadão. Elas podem ser de cunho cultural, político e social. A partir delas são definidos os papéis de cada membro da comunidade para acompanhar o PPP dentro da organização pedagógica. Este elemento encontrava-se contemplado no PPP da escola. Tanto na apresentação da escola, quanto na parte dos princípios pedagógicos, as finalidades estavam claramente descritas. A estrutura organizacional, que é composta por duas

\section{plupais}


estruturas: administrativa e pedagógica. A administrativa organiza o aspecto físico, como recursos humanos, financeiros e materiais. A pedagógica, lida com currículo, processo de ensino aprendizagem, além das interações políticas, o ensino aprendizagem e o currículo (PAIVA, 2018).

Quanto ao currículo, de acordo com Veiga (2013), necessita ser interpretado, enquanto integrante ideológico, não possuir neutralidade, deve estar ausente do contexto social, e é o tipo de organização curricular que a escola deve adotar para fazer parte do controle social. Percebeu-se que estes três elementos estavam devidamente contemplados no PPP, principalmente em relação ao currículo, com uma detalhada exposição das vivências culturais, previstas por lei para serem vivenciadas no ano letivo.

A avaliação é o processo que fornece uma ponderação periódica, a fim de observar se as finalidades apontadas no PPP estão sendo devidamente contempladas. Deve-se usar dados concretos, registrar o contexto, mudanças ocorridas e posterior proposição de alternativas. No PPP analisado este elemento estava bem presente e atualizado com as instruções normativas estaduais, assim como sistema de aprovação, formas de classificação e reclassificação e formas de registro dos resultados de aprendizagem.

Há, no entanto, três elementos que não constavam do documento: o tempo escolar, as relações de trabalho e o processo de decisão, que são aspectos importantes, porém acabaram sendo omitidos do documento.

O PPP precisa ter definido de que forma as decisões serão tomadas. Mesmo que pareça óbvio para a equipe que elabora o documento de que o processo decisório se dará de forma democrática, é fator legitimador se mencionar que as decisões serão em uma democracia. Para Paiva (2018), as tarefas precisam ocorrer através de decisões formais e hierarquizadas, porém, importa que todos sejam partícipes do processo de decisão e revisão das tarefas específicas e gerais das devidas atribuições, visto que na escola os objetivos são comuns.

Outro aspecto que importa ser contemplado são as relações de trabalho, pois estabelecem as relações de força que se dão na unidade de ensino, mitigam os conflitos e os interesses paralelos, porém devem estar bem explícitas no PPP. (PAIVA, 2018). Ainda para este autor, elas devem ter fundamentação na solidariedade, reciprocidade e participação coletiva, em oposição a uma

\section{plurais}

Salvador, v. 5, n.3, p. 200-222, set./dez. 2020

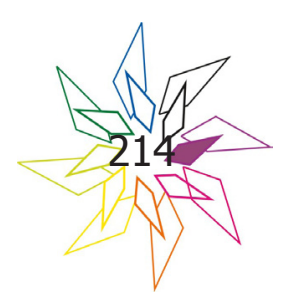


divisão de trabalho, alicerçada na atitude solidária, na reciprocidade e na participação coletiva, contrapondo-se à divisão do trabalho.

O tempo escolar também é um elemento que não foi bem representado no PPP, com exceção de uma tabela com o horário do expediente da escola. A organização do tempo se dá usualmente ao se cumprir atividades dentro dos horários, marcando a rigidez e a fragmentação das disciplinas hierarquizadas, isso interfere na integração do currículo (PAIVA, 2018). No entanto, ele é importante, principalmente no contexto da escola integral.

Para Paiva (2018), o tempo escolar faz parte da organização do trabalho pedagógico e tem como referência o calendário escolar oficial das Secretarias de Educação, que organiza, em geral, o período letivo dos bimestres, das férias, feriados e datas comemorativas. São estabelecidas também a carga horária, as disciplinas e o número de aulas semanais, de acordo com a modalidade de ensino. No entanto, cabe aqui uma ressalva de que, devido à dinâmica variável da rotina escolar, durante o ano letivo, torna-se inviável prever a cada ano no PPP, as datas referentes às atividades pedagógicas e feriados civis ou religiosos.

Diante do que se observou a partir das contribuições de Veiga (2013) e Paiva (2018), percebe-se que o PPP da escola pesquisada, necessita de uma reformulação maior em sua própria estrutura. Considerando-se o modelo atual, pode-se fazer uma reelaboração de suas partes constituintes, a partir dos autores supracitados, tornando o documento mais completo.

\section{A conclusão do processo de revisão do PPP}

No processo de revisão procedeu-se a uma leitura atenta, para se identificar no texto do projeto de que forma o ato situacional, de apresentação da realidade global e local da escola havia sido feito. De acordo com Veiga (2013) o ato situacional faz a descrição do contexto real do momento e revela o conflito e a contradição por trás da prática pedagógica. Ao fazer isto, se compreende melhor a situação, para só então fazer uma reformulação da situação e fazer a "reflexão teórico-prática". A partir desta reflexão, procedeu-se às inserções da EI, de acordo com cada parte do PPP.

Estas foram as principais alterações propostas:

\section{plurais}




\section{- A necessidade de proporcionar ao estudante uma formação plena}

$\mathrm{Na}$ apresentação do PPP foi apontada a necessidade de proporcionar ao estudante uma formação plena, e na sua dimensão estética, o desenvolvimento na sua inteireza, preconizadas por Paulo Freire. Ainda se destacou que a escola é um espaço em que as experiências humanas são produzidas, contestadas e legitimadas. E que suas ações resultam de conflitos, os quais se dão em meio ao quadro de diversidades e desigualdades, presentes no chão da escola, e fazem parte de um processo chamado convivência.

\section{- O Aprender a Conviver nos princípios educacionais e filosóficos}

Na parte dos princípios educacionais e filosóficos da escola, foi dada ênfase no Aprender a Conviver, da Educação Interdimensional, o qual corresponde ao indicador mais evidente da qualidade na formação integral do jovem estudante, visto que constitui a liga entre os demais pilares e representa a presença da cultura de paz na escola. É neste aprendizado do viver juntos, que os estudantes desenvolvem a tolerância e o respeito mútuo.

\section{- Princípios pedagógicos}

No que se refere aos princípios pedagógicos, pensou-se uma nova educação, voltada ao desenvolvimento pleno do ser humano, que ajude jovens adolescentes a sonhar os próprios sonhos e a transformá-los em realidade, através de seu Projeto de Vida. Uma nova escola que utilize um currículo baseado nos Quatro Pilares da Educação, voltado para o desenvolvimento das competências e habilidades necessárias ao jovem para que tenha sucesso na sociedade da informação do século 21 .

\section{- Nova metodologia de trabalho}

O projeto já destacava o tipo de estudante que se almeja para a escola, que adota uma nova metodologia de trabalho, voltada à busca de novas maneiras de ensinar, aprender e pesquisar, nas quais o professor crie ambiente e oportunidades de aprendizagem na forma de projetos de aprendizagem de natureza transdisciplinar e desenvolva seu papel junto aos alunos como apoiador, facilitador e incentivador. Este aluno deve ser autônomo, ao demonstrar responsabilidade na construção de sua história, um protagonista no processo de seu desenvolvimento.

\section{plurais}

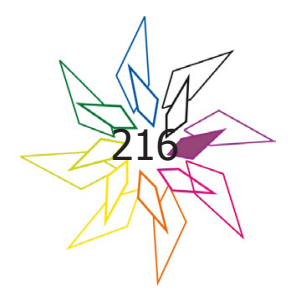


- A prática da mediação de conflitos

A prática da mediação de conflitos foi inserida nos princípios pedagógicos, por possibilitar o estabelecimento de um clima escolar, que reflita uma cultura de paz, onde os conflitos sejam mediados no sentido de promover respeito, tolerância e aprendizado de uma boa convivência na comunidade escolar. A finalidade da escola deve ser então, de não somente transmitir o conhecimento formal, mas também preparar o indivíduo para conviver com seus pares no âmbito social, assim como para o mundo do trabalho.

- Pedagogia da Presença e Protagonismo Juvenil como premissas

As estratégias relacionadas ao Aprender a Conviver, Pedagogia da Presença e Protagonismo Juvenil, foram propostas como premissas do PPP da escola. A prática da presença educativa, enquanto exercício perene de aproximação e distanciamento, assim como momento do educador se aproximar e estabelecer uma relação calorosa, empática e significativa com o educando, aliada à participação ativa e construtiva do jovem protagonista na vida da escola, da comunidade ou da sociedade mais ampla, demonstra a preocupação da gestão e docentes em ter na instituição o jovem como fonte de iniciativa, de liberdade e de compromisso.

\section{- Princípios de Convivência Social}

Finalmente, no item de Princípios de Convivência Social, de alunos e professores, ratificou-se o direito do aluno a uma convivência desejável e ao desenvolvimento da autonomia pessoal e coletiva. Quanto aos docentes, destacou-se o compromisso com a promoção de princípios de convivência, que garantam a seus alunos um clima escolar pacífico e dialético, marcados pela aceitação das diferenças; a valorização do outro; o incentivo à criatividade; a prática de autoavaliação; a valorização da aprendizagem e não apenas do ensino; o incentivo ao trabalho em equipe; o Protagonismo juvenil; a presença educativa e por fim, a formação integral do educando.

É importante destacar que não se chegou aos resultados obtidos, após a proposta de reformulação do PPP, visto que a mesma foi entregue à gestão da escola pesquisada, no entanto não houve retorno a respeito de sua implementação. Todavia, acreditamos que o objetivo foi alcançado, pois pudemos oferecer à escola o fruto de nossa pesquisa, como forma de inserção social.

\section{plurais}




\section{Considerações Finais}

O objetivo deste artigo foi, então, apontar propostas de melhoria na organização da prática pedagógica de uma escola de referência em ensino médio, a qual faz parte do Programa de Educação Integral, no estado de Pernambuco, através da estratégia do aprender a conviver, da Educação Interdimensional. A proposta de reorganização ou revisão do PPP, procurou distanciar-se da visão de um projeto engessado e bem guardado nos arquivos da instituição. Buscou-se, desde sua concepção, retirar da Educação Interdimensional e suas práticas de convivência, o caráter pitoresco que parece ser demonstrado na rotina escolar. Era preciso que tal proposta desse ao PPP um referencial robusto, que ratificasse os esforços da gestão em oferecer aos estudantes uma educação de qualidade social, em uma perspectiva democrática e emancipadora.

Para Veiga (2013), o PPP consiste de um processo de reflexão e discussão perenes, em que a intencionalidade da escola seja levada a termo. Este refletir foi considerado para que as decisões tomadas no sentido de ajudar na organização pedagógica da escola, fossem as mais autênticas possíveis. Imprimindo um caráter intencional e propositivo a cada tópico nomeado.

Vale destacar que é função apriorística do PPP, particularmente na área pedagógica, organizar a escola, com vistas ao processo de aprendizagem e a prática democrática (PAIVA, 2018). Ou seja, as ações descritas no PPP, referentes à reorganização pedagógica, refletem o objetivo do projeto. Ainda segundo este autor, a escola deve garantir esta organização junto a seus atores: gestão, docentes, estudantes e demais membros da comunidade, para a formação humanística do cidadão.

Ao se pensar na forma como ficará a estrutura organizacional de uma escola integral, tornase importante observar que não se pretende uma escola apenas com carga horária estendida, em que os estudantes terão mais tempo para estudar. Importa que se contemple de fato a oferta de um tempo pedagógico que desenvolva a integralidade do indivíduo. Há uma lógica inversa, em alguns modelos pedagógicos, que primeiro define a quantidade de tempo na escola, para depois se definir a forma do currículo se adequar a este tempo, e só então como este se articulará ao projeto escolar (ICE, 2015).

O planejamento da reorganização de uma escola em tempo integral deve então se basear em uma série de questionamentos responsáveis, avaliando a atual estrutura da escola, se ela é viável

\section{plurais}

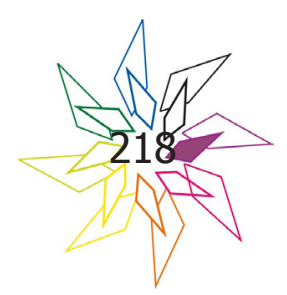


ao aluno, se viabiliza sua formação cidadã, cumprindo seus objetivos com ensino de qualidade, superando ainda a inércia do que Paiva (2018, p. 56) chama de "poder central", que prioriza o tempo, a ordem e a disciplina.

Asseguradas as bases estruturais da reorganização do PPP, a partir do que foi evidenciado acima, é momento de voltar-se mais uma vez às bases epistemológicas que podem representar as reais alterações no projeto da escola. A primeira delas, presente em grande parte da proposta e um dos referenciais da pesquisa, o pilar do aprender a conviver resume a força mediadora da EI, pois proporciona aos estudantes a competência de se relacionar com seus pares, resolvendo conflitos e aprendendo a viver em sociedade.

Sua pertinência no PPP se justifica pela necessidade atual de se valorizar a natureza humana, caracterizada pelo estabelecimento de vínculos e laços, assim como pela ideia de que a existência humana se dá a partir da comunicação e diálogo. Aprender a viver junto é imprescindível, pois reafirma a condição que torna todos os seres humanos iguais, que é a consciência da incompletude e impermanência (ICE, 2015).

As ações para promover o Projeto de Vida do educando foram introduzidas na proposta, ao se perceber durante a pesquisa que, embora esteja prevista no currículo da escola, esta atividade não vinha sendo conduzida pelos professores. Quando bem elaborado e coordenado, o Projeto de Vida facilita ao aluno a escolha de sua carreira após a escola, ou norteia seus rumos no mundo do trabalho.

O jovem que desenvolve a visão do próprio futuro, e consegue realizá-la, atua plenamente nas dimensões, pessoal, social e produtiva, com iniciativa, liberdade e compromisso, "para fazer escolhas, atuando de maneira autônoma, solidária e competente sobre os contextos e desafios, limites e possibilidades advindos deste século.”(ICE, 2015,p. 10)

Enquanto o educando é o meio, a autonomia é o fim na missão de uma escola integral (ICE, 2015). Esta capacidade de demonstrar iniciativa e responsabilidade nas atitudes é desenvolvida por meio das práticas de protagonismo juvenil, uma das premissas indicadas na reorganização do PPP da escola.

O protagonismo se refere aos procedimentos, movimentos e dinâmica social e educativa em que os estudantes adquirem vez nas ações (IDEM). Para Costa (2006) o atual cenário mun-

\section{plurais}


dial exigirá criatividade dos jovens, que serão parte da solução, não do problema, ao vivenciar situações reais em todas as áreas de sua vida. Isto é o que se espera que venha a se concretizar na escola pesquisada.

A segunda premissa preconizada na proposta é a pedagogia da presença, que requer, de acordo com Costa (2001), a participação integral do educador na sua prática educativa. Sem isto, esta presença "não passará de um rito despido de significação mais profunda, reduzindo-se à mera obrigação funcional ou a uma forma qualquer de tolerância e condescendência,..." (COSTA, 2001, p. 25)

Importa também que a presença pedagógica se faça presente em atitudes que envolvam participação da equipe gestora e docente, e que possam extrapolar os limites da sala de aula, através de respeito, estima e amizade entre educadores e educandos (ICE, 2015).

A sala de aula é por sua vez, não apenas palco para a transmissão de conhecimento e habilidades para se executar com competência as tarefas do mundo do trabalho, mas prioritariamente, dentro deste contexto emancipatório, de afirmar o valor humano e sua contribuição na vida pessoal, social e produtiva (IDEM). Este conjunto de conceitos elencados representa a possibilidade de que a proposta ao PPP da escola, engloba uma série de ações concretas, que poderá mudar a forma como a instituição tem compreendido a EI e a formação moral e intelectual de seus estudantes.

\section{REFERÊNCIAS}

ALARCÃO, Isabel. Escola reflexiva e nova racionalidade. P Alegre: Artmed Editora, 2001.

BRASIL, Lei n. 9.394, de 20 de dezembro de 1996. Lei de Diretrizes e Bases da Educação Nacional (LDBEN). Estabelece as diretrizes e bases da educação nacional. Brasília, DF: MEC, 1996.

BRASIL. Lei $\mathbf{n}^{\mathbf{0}} \mathbf{1 3 . 0 0 5} / \mathbf{2 0 1 4}$. Aprova o Plano Nacional de Educação - PNE e dá outras providências. 2014. Disponível em: http://pne.mec.gov.br/18-planos-subnacionais-de-educacao/543-plano-nacional-de-educacao-lei-n-13-005-2014. Acesso em 11 out. 2019.

BRASIL. LEI No 13.415, de 16 de fevereiro de 2017, 2019. Disponível em: http://novoensinomedio.mec.gov.br/\#!/marco-legal. Acesso em: 12 abr. 2019.

COSTA, Antonio Carlos Gomes da, 1949 - Pedagogia da Presença: da solidão ao encontro. Belo Horizonte: Modus Faciendi, 2001. 140p. $2^{\mathrm{a}}$ ed.

\section{plurais}

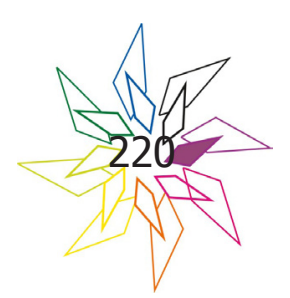


COSTA, Antonio Carlos Gomes da., VIEIRA, Maria Adenil. Protagonismo Juvenil: adolescência, educação e participação democrática. São Paulo: FTD/Fundação Odebrecht, 2006.

COSTA, Alfredo Gomes da. Educação Integral: dicas práticas para a ação. 2016. Disponível em: https://alfredogomesdacosta.com.br/educacao-integral-dicas-praticas-para-a-acao Acesso em: 24 abr. de 2019.

DUTRA, Paulo Fernando Vasconcelos. Módulo de Educação Integral e Profissional: PROGEPE [Programa de Formação de Gestores Educacionais de Pernambuco] / Paulo Fernando Vasconcelos Dutra; Maria de Araújo Medeiros de Souza, rev. 2.ed. Recife: Secretaria de Educação e Esportes de Pernambuco, 2019.

FONSECA, M.; OLIVEIRA, J. F.; TOSCHI, M. S. As tendências da gestão na atual política educacional brasileira: autonomia ou controle? In: BITTAR, M.; OLIVEIRA, J. F. Gestão e políticas da educação. Rio de Janeiro: DPA Editores, 2004.

GADOTTI, M. Perspectivas Atuais da Educação. Porto Alegre: Artes Médicas Sul, 2000.

GADOTTI, Moacir. Educação Integral no Brasil: inovações em processo. Educação Cidadã; 4São Paulo: Editora e Livraria Instituto Paulo Freire, 2009.

ICE, Modelo pedagógico - Princípios Educativos. Instituto de Corresponsabilidade na Educação. Recife, 2015. Disponível em: http://www.secti.ma.gov.br/files/2016/10/MP-PRINCIPIOS-EDUCATIVOS.pdf. Acesso em 19 fev. 2019.

ICE. Atuação do ICE. Instituto de Corresponsabilidade pela Educação, 2019. Disponível em: http://icebrasil.org.br/atuacao/. Acesso em: 12 abr. 2019.

LIBÂNEO, José Carlos, Organização e Gestão da Escola: teoria e prática. Goiânia: Editora Alternativa, 2001.

PAIVA, W. J. A. Caminhos para construção do Projeto Político-Pedagógico nas escolas de Referência em Ensino Médio de Pernambuco. 133 f. Dissertação (Mestrado em Educação) - Universidade de Pernambuco, Nazaré da Mata, 2018.

RODRIGUES, L. A. R. Configurações da gestão escolar nos sistemas municipais e estadual em Pernambuco. Cadernos do Tempo Presente, n. 23, p. 03-19, mar. /abr. 2016

SPÓSITO, M. P. Educação, gestão democrática e participação popular. In: BASTOS, J. B. (org.) Gestão democrática. Rio de Janeiro: DPA, 2005. 
SHIROMA, E. O.; CAMPOS, R. F. La resignificación de la democracia escolar mediante el discurso gerencial: liderazgo, gestión democrática y gestión participativa. In: FELDFEBER, M.; OLIVEIRA, D.A. (orgs.). Políticas educativas y trabajo docente: Nuevas regulaciones, Nuevos sujetos? 1 ed. Buenos Aires: Ediciones Novedades Educativas, 2006, p. 221-237.

SILVA, Valter Ramos da. A Participação Docente na Gestão da Escola de Educação Integral no Município de Itaquitinga- PE. Dissertação (Mestrado em Educação). Universidade de Pernambuco. Nazaré da Mata, 2018.

TINEU, Maia D. et al. PROJETO POLÍTICO PEDAGÓGICO, UM DESAFIO INOVADOR NO AMBIENTE ESCOLAR. XVII Encontro Latino Americano de Iniciação Científica, XIII Encontro Latino Americano de Pós-Graduação e III Encontro de Iniciação à Docência - Universidade do Vale do Paraíba. 2013. Disponível em: http://www.inicepg.univap.br/cd/INIC_2013/ anais/arquivos/0534_0425_01.pdf Acesso em: 28 fev. 2019.

VEIGA, I. P. A. Projeto Político-Pedagógico: uma construção possível. Campinas-SP, Editora Papirus, 2013.

VEIGA, I. P. A. Inovação e projeto político-pedagógico: uma relação regulatória ou emancipatória? Cad. Cedes, Campinas, v. 23, n. 61, p. 267-281, dez. 2003.

Recebido em: 01 de junho de 2020.

Inserido em: 15 de outubro de 2020. 